\title{
MicroRNA-92b promotes cell proliferation and invasion in osteosarcoma by directly targeting Dickkopf-related protein 3
}

\author{
QING WU ${ }^{1 *}$, WEI ZHOU ${ }^{2 *}$, QIONG FENG $^{3}$, XING LIU $^{1}$, YANFEI XIONG $^{4}$ and $\mathrm{HUI} \mathrm{LI}^{5}$ \\ Departments of ${ }^{1}$ Orthopedics and ${ }^{2}$ Vascular Surgery, Second Affiliated Hospital of Nanchang University; ${ }^{3}$ Nursing School, \\ Nanchang University, Nanchang, Jiangxi 330006; ${ }^{4}$ Department of Orthopedics, Jing An Hospital, Yichun, Jiangxi 330600; \\ ${ }^{5}$ Department of Immunology and Microbiology, Medical School of Jishou University, Jishou, Hunan 416000, P.R. China
}

Received August 31, 2016; Accepted May 11, 2017

DOI: $10.3892 /$ etm.2017.5356

\begin{abstract}
Deregulation of microRNA-92b (miR-92b) has been implicated in osteosarcoma. However, the underlying regulatory mechanism of $\mathrm{miR}-92 \mathrm{~b}$ in osteosarcoma growth and metastasis remains largely unclear. In the present study, reverse transcription-quantitative polymerase chain reaction and western blotting were used to measure mRNA and protein expression. MTT and Transwell assays were conducted to determine cell proliferation and invasion, and a luciferase reporter assay was performed to confirm the association between miR-92b and Dickkopf3-related protein (DKK3). The results demonstrated that miR-92b was significantly upregulated in osteosarcoma tissues compared with matched adjacent non-tumor tissues. Additionally, high miR-92b levels were significantly associated with lung metastasis and advanced tumor, node, metastasis stage $(\mathrm{P}<0.05)$ but not with age, sex, tumor size, location, serum lactate dehydrogenase or serum alkaline phosphatase. miR-92b expression was also significantly upregulated in osteosarcoma cell lines compared with normal osteoblast cells. Knockdown of miR-92b significantly inhibited the proliferation and invasion of osteosarcoma U2OS cells $(\mathrm{P}<0,01)$. By contrast, overexpression of miR-92b significantly increased U2OS cell proliferation and invasion $(\mathrm{P}<0.01)$. DKK 3 was identified as a target gene of miR-92b and it was demonstrated that DKK3 expression was negatively regulated by $\mathrm{miR}-92 \mathrm{~b}$ in U2OS cells. Restoration of DKK 3 expression abrogated the increased proliferation and invasion of U2OS cells induced by miR-92b overexpression. Notably, DKK3 was significantly downregulated in osteosarcoma tissues compared with adjacent non-tumor tissues and
\end{abstract}

Correspondence to: Professor Qiong Feng, Nursing School, Nanchang University, 461 Bayi Road, Nanchang, Jiangxi 330006, P.R. China

E-mail: fengqiong2016@qq.com

*Contributed equally

Key words: osteosarcoma, microRNA, proliferation, invasion, Dickkopf-related protein 3 its expression was inversely correlated to miR-92b levels in osteosarcoma tissues. Taken together, these data indicate that miR-92b promotes cell proliferation and invasion in osteosarcoma by targeting DKK3. Therefore, miR-92b may become a potential therapeutic target for osteosarcoma.

\section{Introduction}

Osteosarcoma is the most common cancer in the bone and mainly occurs in regions undergoing active bone growth and repair $(1,2)$. Despite improvements in the efficacy of surgery combined with radiotherapy and/or chemotherapy, the 5-year survival rate of patients with osteosarcoma remains poor, primarily due to recurrence and metastasis $(3,4)$. Therefore, identifying the molecular mechanisms underlying osteosarcoma growth and metastasis is important to facilitate the development of effective therapeutic strategies to treat osteosarcoma.

MicroRNAs (miRs) are a class of small non-coding RNAs that regulate gene expression by directly binding to the 3'-untranslated region (UTR) of their target mRNAs, resulting in either mRNA degradation or the inhibition of translation (5-7). It has been demonstrated that miRs are involved in a variety of biological processes by regulating the expression of their targets, including mRNAs involved in cell survival, differentiation, proliferation, apoptosis, migration and angiogenesis (6,8-10). Furthermore, deregulated miRs have been identified in different types of cancer, such as osteosarcoma and miRs may be used as potential diagnostic and therapeutic targets for osteosarcoma (11-14). miR-133b and miR-503 are markedly downregulated in osteosarcoma tissues compared with adjacent non-tumor tissues and their downregulation is associated with the malignant progression of osteosarcoma and poor overall survival of patients (15). Furthermore, it has been determined that miR-199a-3p is significantly downregulated in osteosarcoma and negatively regulates the proliferation and migration of osteosarcoma cells (16).

Among these miRs, it has been observed that miR-92b serves a role in certain types of human cancer $(17,18)$. miR-92b promotes the proliferation, migration and invasion of glioma cells, and induces apoptosis via regulation of the phosphatase and tensin homolog (PTEN)/protein kinase B signaling pathway (17). Additionally, miR-92b represses the invasion 
and metastasis of esophageal squamous cell carcinoma (ESCC) in vitro and in vivo, and higher expression of miR-92b in ESCC tissue is inversely correlated with lymph node metastasis and indicates better patient prognosis (18). Recently, it has been demonstrated that miR-92b promotes the malignant phenotype of osteosarcoma cells by inhibiting the expression of reversion-inducing, cysteine-rich protein with kazal motifs (RECK) (19). As each miR may have multiple target genes, it remains to be clarified whether there are other targets of miR-92b in osteosarcoma cells.

The present study aimed to investigate the clinical significance and regulatory mechanism of miR-92b in osteosarcoma. The expression of miR-92b in osteosarcoma tissues and cell lines was examined, and the potential target gene of miR-92b was explored.

\section{Materials and methods}

Tissue collection. A total of 58 primary osteosarcoma tissues and matched adjacent non-tumor tissues were collected from patients (35 males and 23 females; mean age, 31.4 years) in the Second Affiliated Hospital of Nanchang from April 2008 to September 2015. Prior to surgical resection, no patients received radio- or chemotherapy. Tissues were immediately snap-frozen in liquid nitrogen following surgical resection and stored in liquid nitrogen. The clinicopathological characteristics of patients included in the present study are summarized in Table I. The current study was approved by the Ethics Committee of the Second Affiliated Hospital of Nanchang University (Nanchang, China) and informed consent was obtained from all participants.

Cell culture. The human osteoblast cell line hFOB and the osteosarcoma cell lines U2OS, Saos-2, MG63 and SW1353 were purchased from the Cell bank of the Chinese Academy of Sciences (Shanghai, China). All cell lines were cultured in Dulbecco's Modified Eagle's medium (DMEM; Thermo Fisher Scientific, Inc., Waltham, MA, USA) supplemented with $10 \%$ fetal bovine serum (Thermo Fisher Scientific, Inc.) in a $37^{\circ} \mathrm{C}$ humidified atmosphere of $5 \% \mathrm{CO}_{2}$.

Cell transfection. U2OS cells were transfected with miR-92b inhibitor or negative control (NC) inhibitor; miR-92b mimic or scramble miR mimic (miR-NC); or pcDNA3.1-DKK3 expression plasmid using Lipofectamine ${ }^{\circledR} 2000$ (Thermo Fisher Scientific, Inc.) according to the manufacturer's instructions. Following $48 \mathrm{~h}$ transfection, levels of miR-92b or DKK3 expression were determined.

Reverse transcription-quantitative polymerase chain reaction (RT-qPCR). Total RNA was extracted using TRIzol ${ }^{\circledR}$ Reagent (Thermo Fisher Scientific, Inc.) according to the manufacturer's instructions. To detect miR expression, RT-qPCR was performed using the All-in-One ${ }^{\mathrm{TM}}$ miRNA qRT-PCR Detection kit (GeneCopoeia, Inc., Rockville, MD, USA) and an ABI 7500 thermocycler (Applied Biosystems; Thermo Fisher Scientific, Inc.) according to the manufacturer's instructions. The thermocycling conditions were as follows: $95^{\circ} \mathrm{C}$ for $10 \mathrm{~min}$, and 45 cycles of denaturation at $95^{\circ} \mathrm{C}$ for $15 \mathrm{sec}$ and annealing/elongation at $60^{\circ} \mathrm{C}$ for $15 \mathrm{sec}$. The U6 gene was used as an internal control. The primers for miR-92b (cat. no. HmiRQP0834) and U6 (cat. no. HmiRQP9001) were purchased from Guangzhou Fulengen Co., Ltd. (Guangzhou, China). To detect mRNA expression, total RNA was converted to cDNA using the PrimeScript 1st Strand cDNA Synthesis kit (Takara Bio, Inc., Tokyo, Japan) according to the manufacturer's instructions. A SYBR Green I Real-Time PCR kit (Biomics Biotechnologies, Co., Ltd., Nantong, China) was then used to perform qPCR according to the manufacturer's instructions. GAPDH was used as the internal reference for mRNA. The primers used were as follows: DKK3, forward, 5'-AGG ACACGCAGCACAAATTG-3' and reverse, 5'-CCAGTCTGG TTGTTGGTTATCTT-3'; GAPDH, forward, 5'-ACAACT TTGGTATCGTGGAAGG-3' and reverse; 5'-GCCATCACG CCACAGTTTC-3'. The thermocycling conditions were $95^{\circ} \mathrm{C}$ for $3 \mathrm{~min}$, followed by 40 cycles of $95^{\circ} \mathrm{C}$ for $15 \mathrm{sec}$ and $60^{\circ} \mathrm{C}$ for $15 \mathrm{sec}$. Relative expression was analyzed using the $2^{-\Delta \Delta \mathrm{Cq}}$ method (20).

Western blot analysis. Cells were solubilized in cold radioimmunoprecipitation assay lysis buffer (Beyotime Institute of Biotechnology, Shanghai, China). Protein concentration was determined using the BCA assay kit (Thermo Fisher Scientific, Inc.) and proteins $(50 \mu \mathrm{g})$ were separated with $10 \%$ SDS-PAGE and transferred onto a polyvinylidene difluoride membrane (Thermo Fisher Scientific, Inc.). The membrane was blocked with PBS containing 5\% milk (Yili Group, Beijing, China) for $3 \mathrm{~h}$ at room temperature. Following 3 washes with PBS (Beyotime Institute of Biotechnology), the membrane was incubated with rabbit polyclonal anti-DKK3 antibody (1:100; ab187532; Abcam, Cambridge, MA, USA) or rabbit polyclonal anti-GAPDH antibody (1:50; ab37168; Abcam) at room temperature for $3 \mathrm{~h}$. Following 3 washes with PBS, the membrane was incubated with goat anti-rabbit immunoglobulin G (1:5,000; ab6721; Abcam) at room temperature for $40 \mathrm{~min}$. An ECL kit (Thermo Fisher Scientific, Inc.) was then used to perform enhanced chemiluminent detection. Relative protein expression was presented as the density ratio vs. GAPDH using Image-Pro Plus software 6.0 (Media Cybernetics, Inc., Rockville, MD, USA).

MTT assay. U2OS cell suspension $\left(5 \times 10^{4}\right.$ cells/well) was plated in a 96-well plate, and cultured for $0,24,48$ or $72 \mathrm{~h}$. Subsequently, MTT $(10 \mu \mathrm{l}, 5 \mathrm{mg} / \mathrm{ml})$ was added to each well and then incubated at $37^{\circ} \mathrm{C}$ for $4 \mathrm{~h}$. The supernatant was removed and $100 \mu \mathrm{l}$ dimethyl sulfoxide (Sigma-Aldrich; Merck KGaA, Darmstadt, Germany) was added to each well to dissolve the purple formazan. The absorbance at $570 \mathrm{~nm}$ was measured using the Model 680 Microplate Reader (Bio-Rad Laboratories, Inc., Hercules, CA, USA).

Transwell assay. U2OS cell suspension $\left(1 \times 10^{6}\right.$ cells $\left./ \mathrm{ml}\right)$ was prepared in DMEM, $300 \mu \mathrm{l}$ of which was added to the upper transwell chamber (BD Biosciences, Franklin Lakes, NJ, USA) pre-coated with Matrigel (BD Biosciences). Subsequently, $300 \mu \mathrm{l}$ DMEM with $10 \%$ FBS was added to the lower chamber. Following $24 \mathrm{~h}$ culture at $37^{\circ} \mathrm{C}$, cells that did not invade through the membrane in the filter were lightly wiped using a cotton-tipped swab (BD Biosciences). The filter was then fixed in $90 \%$ alcohol at room temperature for $10 \mathrm{~min}$ and cells were 
Table I. Association between miR-92b expression and clinicopathological characteristics in osteosarcoma.

\begin{tabular}{|c|c|c|c|c|}
\hline Variables & Cases $(n=58)$ & Low miR-92b (n=28) & High miR-92b $(n=30)$ & P-value \\
\hline Age, years & & & & 0.435 \\
\hline$<20$ & 24 & 10 & 14 & \\
\hline$\geq 20$ & 34 & 18 & 16 & \\
\hline Sex & & & & 0.789 \\
\hline Male & 35 & 16 & 19 & \\
\hline Female & 23 & 12 & 11 & \\
\hline Tumor size, $\mathrm{cm}$ & & & & 0.199 \\
\hline$<8$ & 26 & 10 & 16 & \\
\hline$\geq 8$ & 32 & 18 & 14 & \\
\hline Location & & & & 0.781 \\
\hline Femur or tibia & 39 & 18 & 21 & \\
\hline Other & 19 & 10 & 9 & \\
\hline Lung metastasis & & & & 0.011 \\
\hline No & 40 & 24 & 16 & \\
\hline Yes & 18 & & 14 & \\
\hline TNM stage & & & & 0.013 \\
\hline I/IIA & 21 & 15 & 6 & \\
\hline IIB/III & 37 & 13 & 24 & \\
\hline Serum lactate dehydrogenase & & & & 0.184 \\
\hline Normal & 22 & & 14 & \\
\hline Elevated & 36 & 20 & 16 & \\
\hline Serum alkaline phosphatase & & & & 0.795 \\
\hline Normal & & 11 & 13 & \\
\hline Elevated & & 17 & 17 & \\
\hline
\end{tabular}

TNM, tumor node metastasis.

stained at room temperature for 10 min using $0.1 \%$ crystal violet (Beyotime Institute of Biotechnology). Invading cells were observed under an inverted microscope and images were captured.

Bioinformatics predication and luciferase reporter assay. Targetscan (http://www.targetscan.org) was used to predicate the potential targets of miR-92b, according to the manufacturer's instructions. 'Human' was selected as the species and 'miR-92b' was entered. The mutant type (MT) of DKK3 3'UTR lacking complementarity with the miR-92b seed sequence was generated using the QuickChange Site-Directed Mutagenesis kit (Agilent Technologies Inc., Santa Clara, CA, USA), according to the manufacturer's instructions. The wild-type (WT) or MT of DKK3 3'UTR was then cloned downstream of the firefly luciferase coding region of the pMIR-GLOTM Luciferase vector (Promega Corporation, Madison, WI, USA). U2OS cells were co-transfected with WT-DKK3-3'UTR or MUT-DKK3-3'UTR plasmid, and miR-92b mimic or miR-NC, respectively, using Lipofectamine 2000 (Thermo Fisher Scientific, Inc.) according to the manufacturer's protocol. Following $48 \mathrm{~h}$ transfection, luciferase activity was determined using the dual-Luciferase Reporter assay system (Promega Corporation) according to the manufacturer's instruction and normalized to Renilla luciferase activity.

Statistical analysis. The results are expressed as the mean \pm standard deviation of three independent experiments. Student's t test was used to analyze the difference between two groups. One-way analysis of variance with the Tukey post hoc test was used to analyze the differences between more than two groups, and Pearson's correlation analysis was used to look for associations between groups. SPSS 19 (IBM Corp., Armonk, NY, USA) was used to perform statistical analysis. $\mathrm{P}<0.05$ was considered to indicate a statistically significant difference.

\section{Results}

miR-92b is upregulated in osteosarcoma. RT-qPCR was performed to measure miR-92b expression in a total of 58 osteosarcoma tissues as well as matched adjacent normal tissues from patients with osteosarcoma. The results indicated that miR-92b levels were significantly increased in osteosarcoma tissue compared with adjacent normal tissue $(\mathrm{P}<0.01$; 
A

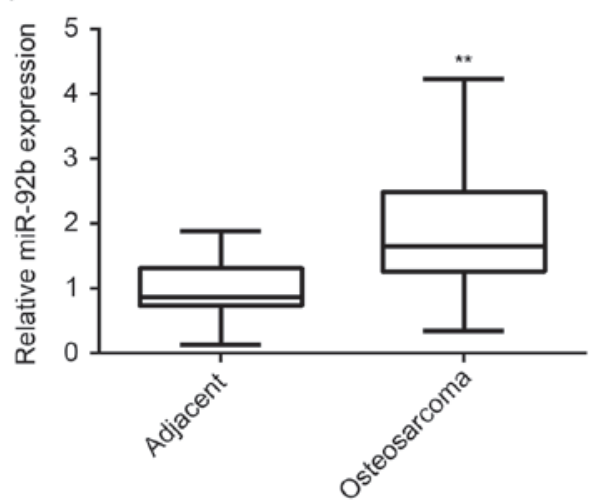

B

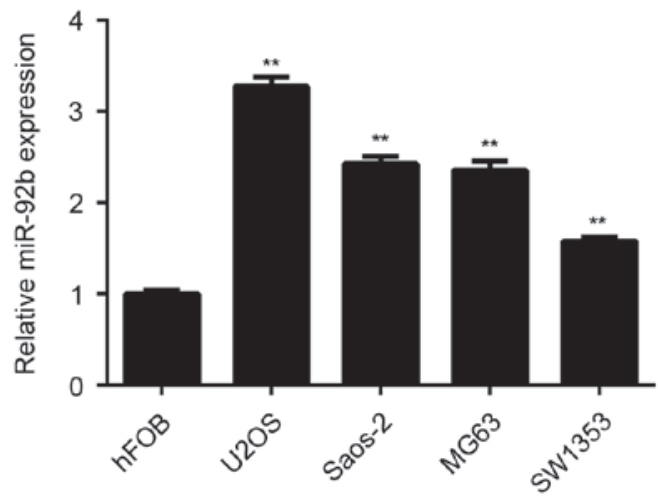

Figure 1. Reverse transcription-quantitative polymerase chain reaction was performed to examine the miR-92b expression in (A) osteosarcoma tissues and matched adjacent non-tumor tissues ( ${ }^{* *} \mathrm{P}<0.01$ vs. adjacent tissue), as well as in (B) osteosarcoma cell lines (U2OS, Saos-2, MG63, and SW1353) and normal osteoblast hFOB cells $\left({ }^{* *} \mathrm{P}<0.01 \mathrm{vs}\right.$. hFOB). The results are expressed as the mean \pm standard deviation. miR, microRNA.

Fig. 1A). Furthermore, it was significantly upregulated in the osteosarcoma cell lines U2OS, Saos-2, MG63 and SW1353, compared with normal osteoblast hFOB cells $(\mathrm{P}<0.01$; Fig. 1B).

Upregulation of miR-92b is associated with osteosarcoma progression. The association between miR-92b expression and clinical characteristics in osteosarcoma was investigated. Mean miR-92b levels were used as the cutoff point and this cutoff point was used to divide patients with osteosarcoma into a high miR-92b expression group and a low miR-92b expression group. A total of 30 patients were in the high miR-92b expression group, whereas 28 patients were in the low miR-92b expression group (Table I). High miR-92b levels were significantly associated with lung metastasis and an advanced clinical stage of osteosarcoma $(\mathrm{P}<0.05$; Table I). However, no significant associations were identified between miR-92b expression and age, sex, tumor size, location, serum lactate dehydrogenase or serum alkaline phosphatase in osteosarcoma (Table $\mathrm{I}$ ). The results demonstrated that upregulation of miR-92b may be associated with osteosarcoma progression.

miR-92b promotes the proliferation and invasion of osteosarcoma cells. The regulatory role of miR-92b in osteosarcoma in vitro was determined using U2OS cells, as miR-92b expression was highest in U2OS cells compared with the other osteosarcoma cell lines. miR-92b expression was upregulated in U2OS cells, thus they were transfected with either miR-92b inhibitor or NC inhibitor. Transfection with miR-92b inhibitor significantly decreased miR-92b expression compared with the NC inhibitor group ( $\mathrm{P}<0.01$; Fig. 2A). MTT and Transwell assays were further conducted to examine cell proliferation and invasion, respectively. miR-92b knockdown significantly decreased U2OS cell proliferation and invasion compared with the NC inhibitor group $(\mathrm{P}<0.01$; Fig. $2 \mathrm{~B}$ and $\mathrm{C})$. This suggests that miR-92b may promote the proliferation and invasion of osteosarcoma cells. To further confirm these results, U2OS cells were transfected with miR-92b mimic or miR-NC. Transfection with miR-92b mimic significantly upregulated miR-92b levels compared with miR-NC transfection $(\mathrm{P}<0.01$; Fig. 2D). Overexpression of miR-92b significantly increased the proliferation and invasion of $\mathrm{U} 2 \mathrm{OS}$ cells $(\mathrm{P}<0.01$; Fig. $2 \mathrm{E}$ and $\mathrm{F}$ ), indicating that $\mathrm{miR}-92 \mathrm{~b}$ promotes the proliferation and invasion of osteosarcoma cells.

$D K K 3$ is a target gene of miR-92b in U2OS cells. The potential target of miR-29b in osteosarcoma cells was investigated. Bioinformatics predication indicated that DKK3 was a putative target of miR-92b (Fig. 3A). Furthermore, overexpression of miR-92b significantly reduced DKK3 expression $(\mathrm{P}<0.01$; Fig. 3B), whereas knockdown of miR-92b significantly increased DKK3 expression in U2OS cells ( $\mathrm{P}<0.01$; Fig. 3C), indicating that the expression of DKK3 is negatively regulated by $\operatorname{miR}-92 b$.

To further investigate the association between miR-92b and DKK3, WT-DKK3-3'UTR and MUT-DKK3-3'UTR luciferase reporter plasmids were generated (Fig. 3D and E). Subsequently, U2OS cells were co-transfected with WT-DKK3-3'UTR or MUT-DKK3-3'UTR luciferase reporter plasmid and miR-92b mimic or miR-NC, respectively. Luciferase activity was significantly decreased in U2OS cells co-transfected with miR-92b mimic and WT-DKK3-3'UTR luciferase reporter plasmid compared with the control group $(\mathrm{P}<0.01$; Fig. 3F). However, luciferase activity was unchanged in cells co-transfected with miR-92b mimic and MUT-DKK3-3'UTR luciferase reporter plasmid compared with the control group (Fig. 3F). Taken together, the aforementioned results demonstrate that DKK3 is a target gene of miR-92b in U2OS cells.

Restoration of DKK3 reverses the increased proliferation and invasion of osteosarcoma cells induced by miR-92b overexpression. It was speculated that DKK3 may be involved in the miR-92b-induced proliferation and invasion of U2OS cells. To clarify this, miR-92b-overexpressing osteosarcoma cells were transfected with pcDNA3.1-DKK3 expression plasmid to restore DKK3 expression. Following transfection, DKK3 expression was significantly higher in the miR-92b+DKK3 group compared with the miR-92b group $(\mathrm{P}<0.01$; Fig. 4A). MTT and Transwell assays indicated that the proliferation and invasion of U2OS cells was significantly decreased in the miR-92b+DKK3 group compared with the miR-92b group $(\mathrm{P}<0.01$; Fig. $4 \mathrm{~B}$ and $\mathrm{C})$. This suggests that restoration of DKK3 expression reverses the increased proliferation and invasion of osteosarcoma cells induced by 


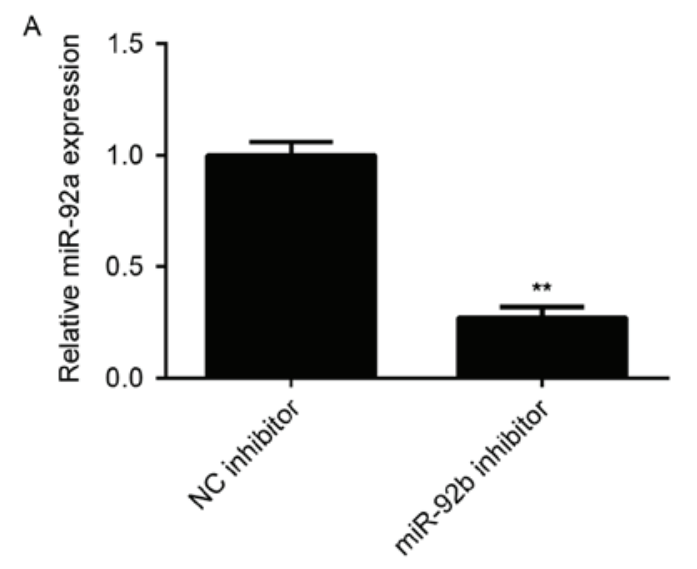

B

C
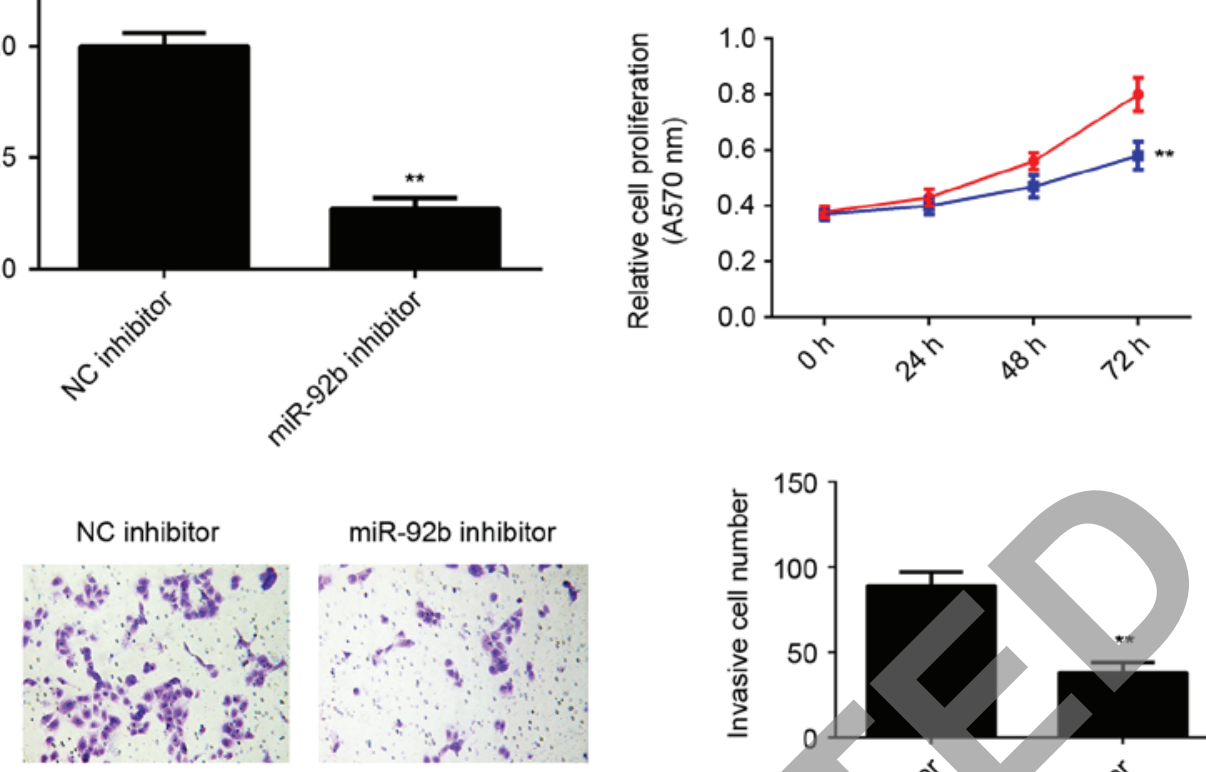

- NC inhibitor

- miR-92b inhibitor

$\mathrm{D}$

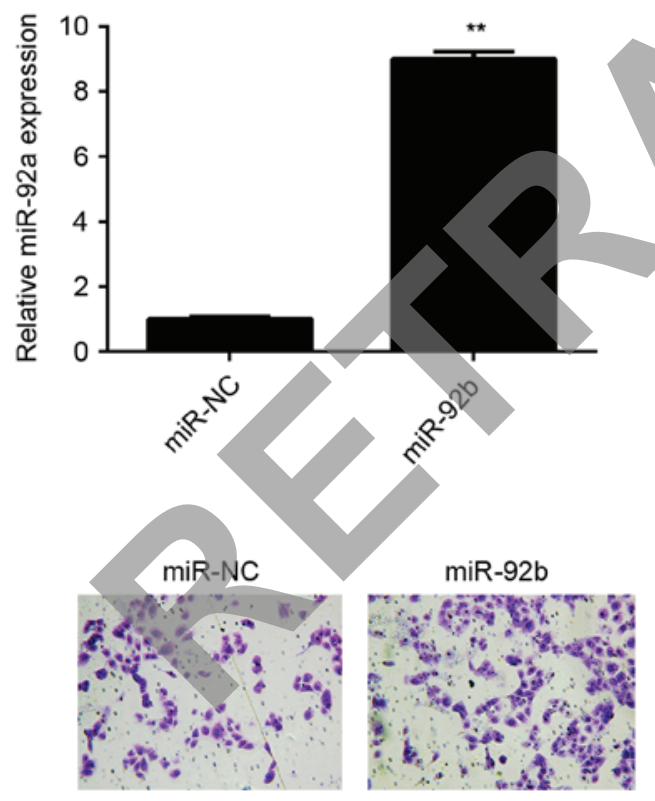

$\mathrm{E}$
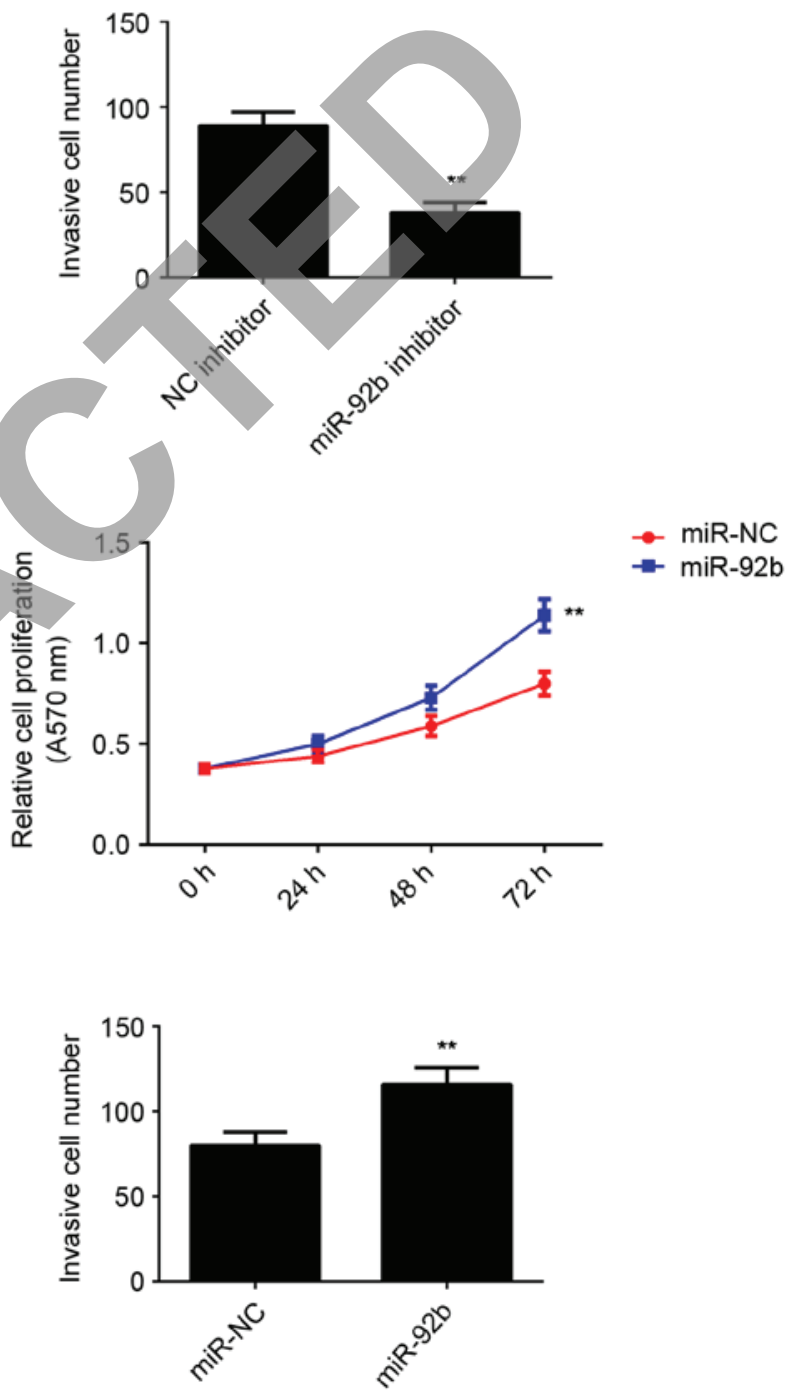

Figure 2. U2OS cells were transfected with miR-92b inhibitor or NC inhibitor. (A) Reverse transcription-quantitative polymerase chain reaction was performed to determine the relative expression of miR-92b. (B) MTT and (C) Transwell assays were performed to examine cell proliferation and invasion, respectively (magnification, $\mathrm{x} 200$ ). ${ }^{* *} \mathrm{P}<0.01$ vs. NC inhibitor. Subsequently, U2OS cells were transfected with miR-92b mimic or miR-NC. (D) RT-qPCR was performed to determine miR-92b expression. (E) MTT and (F) Transwell assays were used to examine cell proliferation and invasion. Results are presented as the mean \pm standard deviation. Magnification, $\mathrm{x} 200$. $^{* *} \mathrm{P}<0.01$ vs. miR-NC. NC, negative control; miR-NC, scramble miR; miR, microRNA.

miR-92b overexpression, suggesting that miR-92b stimulates the proliferation and invasion of osteosarcoma cells, at least partly, by targeting DKK3.

DKK3 expression is downregulated in sarcoma and inversely correlated with miR-92b expression. DKK3 expression was measured in osteosarcoma tissues and cell lines. Levels of DKK3 mRNA were significantly decreased in osteosarcoma tissues compared with adjacent normal tissues $(\mathrm{P}<0.01$; Fig. 5A). DKK3 mRNA was also significantly downregulated in the osteosarcoma cell lines compared with normal osteoblast hFOB cells $(\mathrm{P}<0.01$; Fig. $5 \mathrm{~B})$. Furthermore, an 

Conserved

\begin{tabular}{|c|c|c|c|c|c|c|c|}
\hline & $\begin{array}{l}\text { Predicted consequential pairing of target region (top) } \\
\text { and miRNA (bottom) }\end{array}$ & $\begin{array}{l}\text { Site } \\
\text { type }\end{array}$ & $\begin{array}{c}\text { Context++ } \\
\text { score }\end{array}$ & $\begin{array}{l}\text { Context++ score } \\
\text { percentile }\end{array}$ & $\begin{array}{l}\text { Weighted context+ } \\
\text { score }\end{array}$ & $\begin{array}{l}\text { Conserved branch } \\
\text { length }\end{array}$ & ch $P_{\text {cr }}$ \\
\hline Position 25-32 of DKK3 3' UTR & 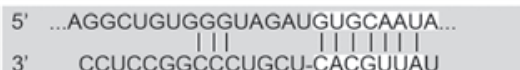 & $8 \mathrm{mer}$ & -0.51 & 99 & -0.51 & 4.155 & 0.86 \\
\hline
\end{tabular}

B
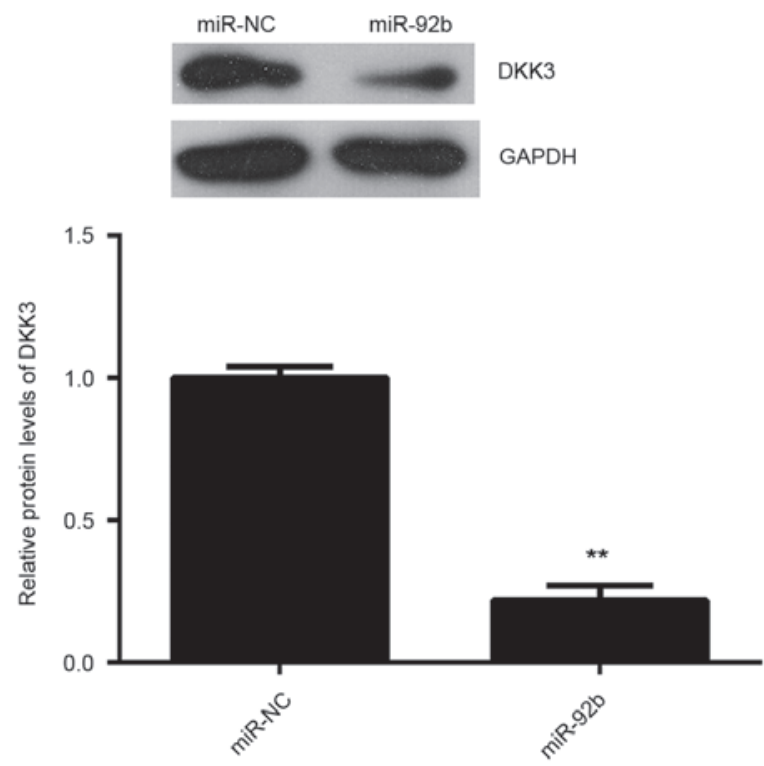

D E Wild type of DKK3 3'UTR $\quad 5^{\prime}$ - A G A U GUGCAAUA-3' miR-92b 3' - U GCUCACGUUAU - 5 Mutant type of DKK3 3'UTR 5' - A G AUCACGUUAU-3'

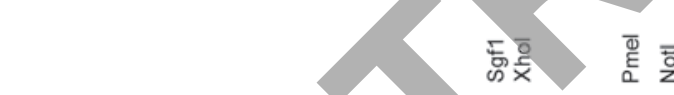

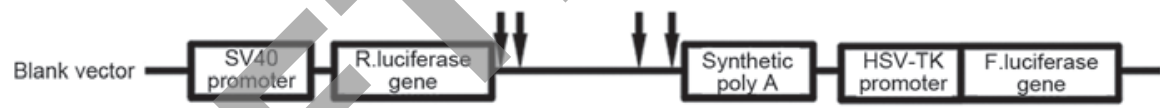

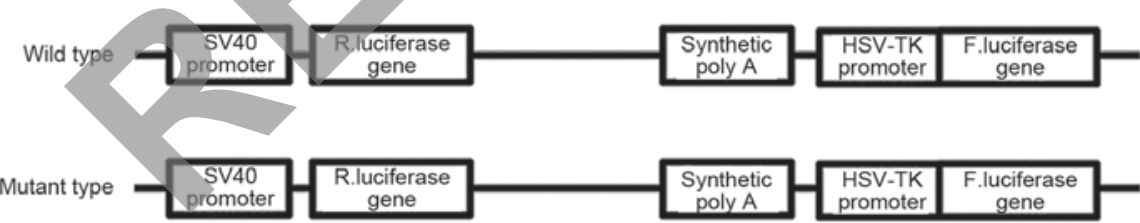
$\mathrm{F}$

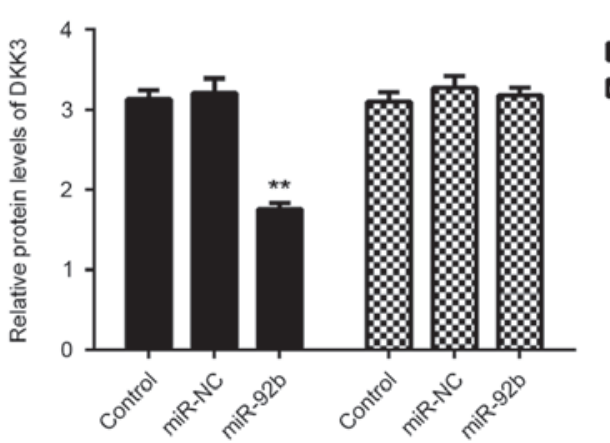

Figure 3. (A) Targetscan software predicated that DKK3 was a putative target of miR-92b. Western blotting was used to measure the expression of DKK3 in U2OS cells transfected with (B) miR-NC and miR-92b mimic, as well as in U2OS cells transfected with (C) NC inhibitor and miR-92b inhibitor. (D and E) Luciferase reporter vectors containing the wild-type and mutant DKK3 3'-UTR were constructed. (F) Luciferase activity was significantly decreased in U2OS cells co-transfected with miR-92b mimic and WT-DKK3-3'UTR reporter plasmid but exhibited no difference in cells co-transfected with miR-92b mimic and MUT-DKK3-3'UTR reporter plasmid, compared with the control group. All results are presented as the mean \pm standard deviation ${ }^{* *} \mathrm{P}<0.01$ vs. Control. UTR, untranslated region; NC, negative control; WT, wild-type; MUT, mutant; DKK3, Dickkopf3-related protein; miR, microRNA. 
A miR-92b miR-92b+DKK3
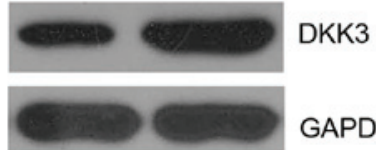

GAPDH

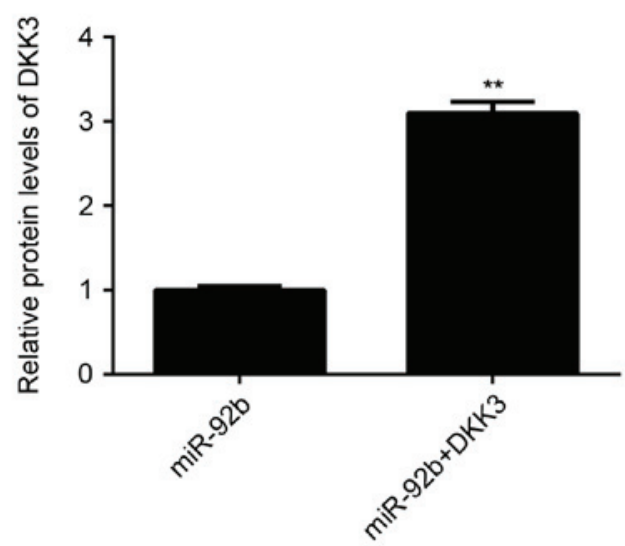

C

miR-92b

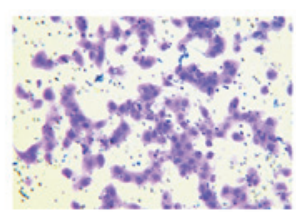

B
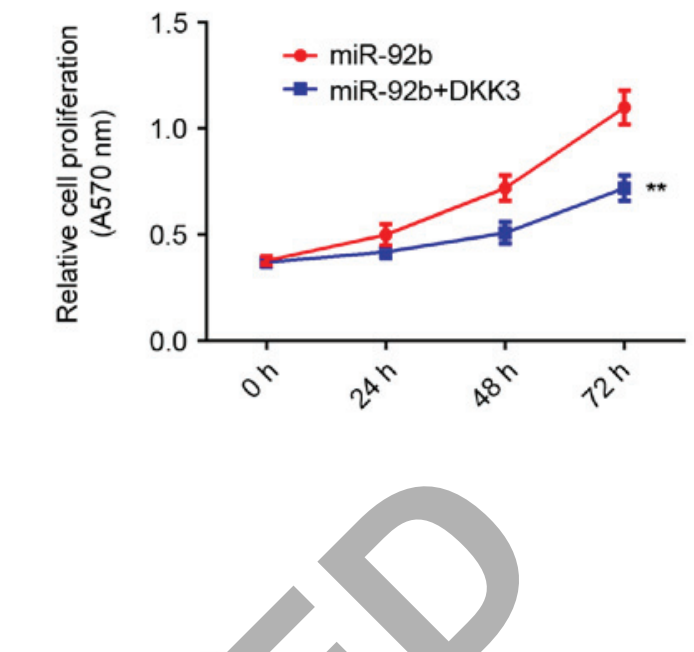

Figure 4. (A) Western blotting was performed to measure DKK3 expression in osteosarcoma cells transfected with miR-92b mimic or co-transfected with miR-92b mimic and DKK3 plasmid. (B) MTT and (C) Transwell assays were used to examine cell proliferation and invasion (magnification, x200). The results are presented as the mean \pm standard deviation ${ }^{*} \mathrm{P}<0.01$ vs. miR-92b. DKK3, Dickkopf3-related protein; miR, microRNA.
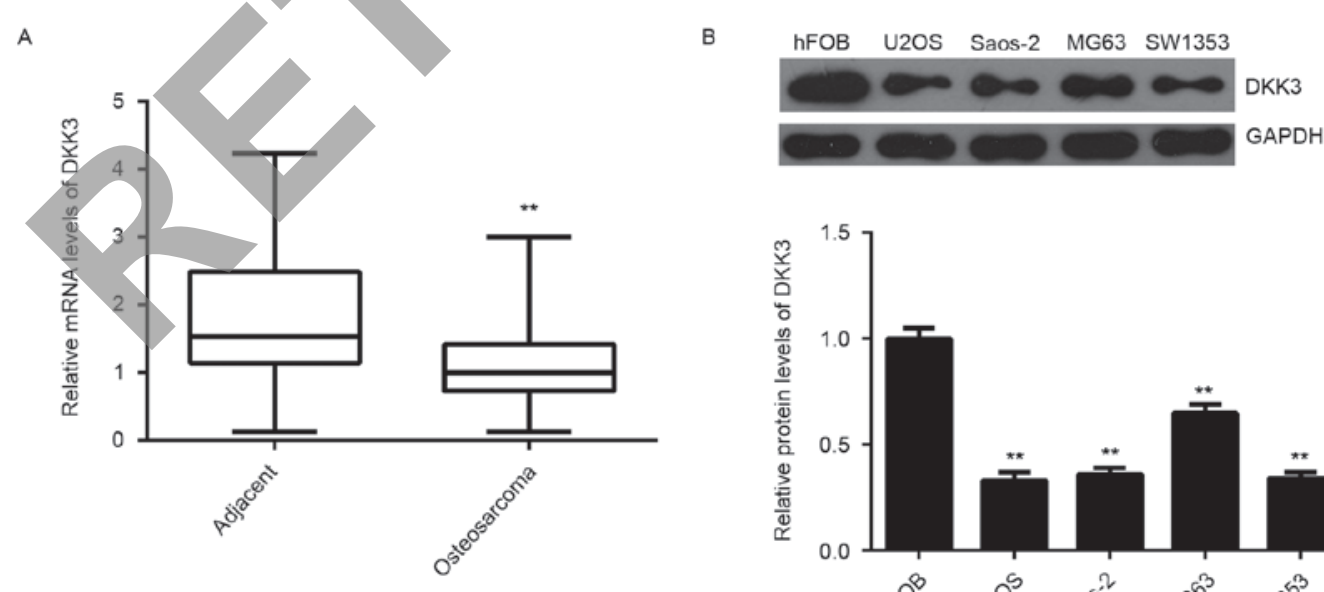

C
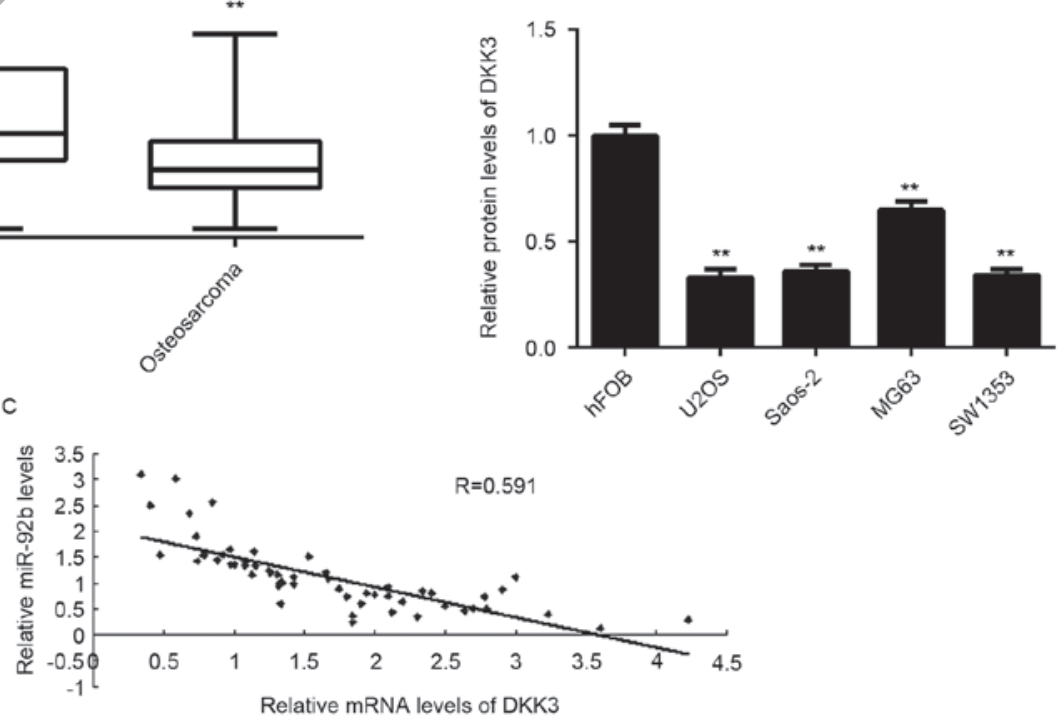

Figure 5. Reverse transcription-quantitative polymerase chain reaction was performed to measure levels of DKK3 mRNA in (A) osteosarcoma tissue and matched adjacent non-tumor tissue ( $\left({ }^{* *} \mathrm{P}<0.01\right.$ vs. adjacent tissue), as well as (B) in the osteosarcoma cell lines U2OS, Saos-2, MG63 and SW1353, compared with normal osteoblast hFOB cells (** $\mathrm{P}<0.01 \mathrm{vs.} \mathrm{hFOB).} \mathrm{(C)} \mathrm{An} \mathrm{inverse} \mathrm{correlation} \mathrm{was} \mathrm{found} \mathrm{between} \mathrm{the} \mathrm{miR-92b} \mathrm{and} \mathrm{DKK3} \mathrm{levels} \mathrm{in} \mathrm{osteosarcoma} \mathrm{tissues.}$ The results are presented as the mean \pm standard deviation. DKK3, Dickkopf3-related protein; miR, microRNA. 
inverse correlation was detected between miR-92b expression and DKK3 mRNA levels in osteosarcoma tissues $(\mathrm{P}<0.01$; Fig. 5C). These results suggest that the decreased expression of DKK3 may be caused by the upregulation of miR-92b in osteosarcoma.

\section{Discussion}

In the present study, the expression, clinical significance and regulatory mechanism of miR-92b in osteosarcoma were measured. The results of the current study demonstrated that miR-92b was significantly upregulated in osteosarcoma tissues and cell lines and that the increased expression of miR-92b was associated with the malignant progression of osteosarcoma. It was also indicated that miR-92b may promote the proliferation and invasion of osteosarcoma cells by directly targeting DKK3. In addition, it was observed that DKK3 was significantly downregulated in osteosarcoma tissues and cell lines, and was inversely correlated with miR-92b levels in osteosarcoma tissues.

The deregulation of miR-92b has been implicated in several different types of human cancer and serves an oncogenic role (21-23). For instance, miR-92b directly targets PTEN, promotes cell growth and induces cisplatin chemosensitivity in non-small cell lung cancer (NSCLC) cells (21). Inhibition of miR-92b suppresses NSCLC cell growth and motility by targeting RECK (22). Additionally, miR-92b functions as a potential oncogene in glioblastomas by targeting SMAD3 (23). However, the underlying regulatory mechanism of miR-92b in osteosarcoma growth and metastasis remains largely unclear. The results of the current study demonstrated that miR-92b is upregulated in osteosarcoma tissues compared with matched adjacent non-tumor tissues, and in osteosareoma cell lines compared with normal osteoblasts. These results are consistent with those of another study by Zhou et al (19), which reported that miR-92b was upregulated in osteosarcoma cell lines and tissues, and that its upregulation was correlated with poor prognosis in osteosarcoma. The current study determined that increased miR-92b expression was significantly associated with advanced clinical stage and lung metastasis, suggesting that upregulation of miR-92b may contribute to the malignant progression of osteosarcoma. Furthermore, it was demonstrated that miR-92b knockdown significantly inhibited U2OS cell proliferation and invasion, whereas overexpression of miR-92b enhanced these cellular events. Similarly, Zhou et al (19) identified that overexpression of miR-92b promotes osteosarcoma cell proliferation, migration and invasion, which were abrogated following miR-92b knockdown. Taken together, the results of the current study and those of previous studies suggest that miR-92b may be used as a therapeutic target to attenuate the growth and metastasis of osteosarcoma.

DKK3 belongs to a member of the dickkopf family and contains two cysteine-rich regions (24). DKK3 interacts with and suppresses the Wnt signaling pathway and participates in embryonic development as well as tumorigenesis $(25,26)$. It has been demonstrated that DKK3 expression is decreased in human cancer and DKK3 also acts as a tumor suppressor $(27,28)$. DKK3 is downregulated in uterine cervical squamous cell carcinoma and this decreased expression is associated with adverse clinical outcomes (27). Lee et al (28) determined that DKK3 expression was downregulated in cervical cancer tissues and cell lines and suppressed the colony formation and cell growth of cervical cancer cells by inhibiting $\beta$-catenin signaling. In the present study, DKK3 was identified as a direct target gene of miR-92b in U2OS cells and DKK3 was negatively regulated by miR-92b at the post-transcriptional level. Furthermore, restoration of DKK3 expression significantly eliminated the promoting effects of miR-92b on U2OS cell proliferation and invasion. These results suggest that miR-92b promotes the proliferation and invasion of osteosarcoma cells by inhibiting DKK3. This association between miR-92b and DKK3 was also identified in glioma (29). Therefore, the results of the current study expand understanding regarding the importance of the miR-92b/DKK3 axis in human cancer.

The current study demonstrated that DKK3 expression was significantly reduced in osteosarcoma tissues compared with adjacent non-tumor tissues, and in osteosarcoma cell lines compared with normal osteoblast cells. It has previously been demonstrated that DKK3 functions as a tumor suppressor in osteosarcoma and suppresses the invasion and motility of osteosarcoma cells by inhibiting the Wnt- $\beta$-catenin pathway (30). Furthermore, an inverse correlation between miR-92b and DKK3 expression in osteosarcoma tissue was detected in the current study, suggesting that the decreased expression of DKK3 may be due to the increased expression of miR-92b in osteosarcoma tissues. The primary limitation of the current study was a lack of information regarding the survival time of patients. In the future, the role of the miR-92b/DKK3 axis in vivo, as well as the molecular mechanism downstream of the miR-92b/DKK3 axis should be studied further.

Taken together, the results of the current study demonstrate that miR-92b expression is upregulated in osteosarcoma and promotes the proliferation and invasion of osteosarcoma cells by directly targeting DKK3. This suggests that miR-92b may be a potential target for the treatment of osteosarcoma.

\section{References}

1. Maximov VV and Aqeilan RI: Genetic factors conferring metastasis in osteosarcoma. Future Oncol 12: 1623-1644, 2016.

2. Zhang J, Yu XH, Yan YG, Wang C and Wang WJ: PI3K/Akt signaling in osteosarcoma. Clin Chim Acta 444: 182-192, 2015.

3. Torre LA, Bray F, Siegel RL, Ferlay J, Lortet-Tieulent J and Jemal A: Global cancer statistics, 2012. CA Cancer J Clin 65: 87-108, 2015.

4. Siegel RL, Miller KD and Jemal A: Cancer statistics, 2015. CA Cancer J Clin 65: 5-29, 2015.

5. Ambros V: The functions of animal microRNAs. Nature 431: 350-355, 2004.

6. Bartel DP: MicroRNAs: Genomics, biogenesis, mechanism, and function. Cell 116: 281-297, 2004.

7. John B, Enright AJ, Aravin A, Tuschl T, Sander C and Marks DS: Human MicroRNA targets. PLoS Biol 2: e363, 2004.

8. Mannavola F, Tucci M, Felici C, Stucci S and Silvestris F: miRNAs in melanoma: A defined role in tumor progression and metastasis. Expert Rev Clin Immunol 12: 79-89, 2016.

9. Calin GA and Croce CM: MicroRNA signatures in human cancers. Nat Rev Cancer 6: 857-866, 2006.

10. Bostjancic E and Glavac D: Importance of microRNAs in skin morphogenesis and diseases. Acta Dermatovenerol Alp Pannonica Adriat 17: 95-102, 2008. 
11. Lee JW, Choi CH, Choi JJ, Park YA, Kim SJ, Hwang SY, Kim WY, Kim TJ, Lee JH, Kim BG and Bae DS: Altered MicroRNA expression in cervical carcinomas. Clin Cancer Res 14: 2535-2542, 2008.

12. Negrini M and Calin GA: Breast cancer metastasis: A microRNA story. Breast Cancer Res 10: 203, 2008.

13. Thompson LD: Osteosarcoma. Ear Nose Throat J 92: 288-290, 2013.

14. Xu H, Mei Q, Xiong $\mathrm{C}$ and Zhao J: Tumor-suppressing effects of miR-141 in human osteosarcoma. Cell Biochem Biophys 69 319-325, 2014

15. Bassampour SA, Abdi R, Bahador R, Shakeri M, Torkaman A, Yahaghi E and Taheriazam A: RETRACTED ARTICLE: Downregulation of miR-133b/miR-503 acts as efficient prognostic and diagnostic factors in patients with osteosarcoma and these predictor biomarkers are correlated with overall survival. Tumour Biol: Aug 16, 2015 (Epub ahead of print).

16. Duan Z, Choy E, Harmon D, Liu X, Susa M, Mankin H and Hornicek F: MicroRNA-199a-3p is downregulated in human osteosarcoma and regulates cell proliferation and migration. Mol Cancer Ther 10: 1337-1345, 2011.

17. Song H, Zhang Y, Liu N, Wan C, Zhang D, Zhao S, Kong Y and Yuan L: miR-92b regulates glioma cells proliferation, migration, invasion, and apoptosis via PTEN/Akt signaling pathway. J Physiol Biochem 72: 201-211, 2016.

18. Ma G, Jing C, Li L, Huang F, Ding F, Wang B, Lin D, Luo A and Liu Z: MicroRNA-92b represses invasion-metastasis cascade of esophageal squamous cell carcinoma. Oncotarget 7 : 20209-20222, 2016

19. Zhou Z, Wang Z, Wei H, Wu S, Wang X and Xiao J: Promotion of tumour proliferation, migration and invasion by miR-92b in targeting RECK in osteosarcoma. Clin Sci (Lond) 130: 921-930, 2016.

20. Soltani S, Mokarian F and Panjehpour M: The expression of CK-19 gene in circulating tumor cells of blood samples of metastatic breast cancer women. Res Pharm Sci 10: 485-496, 2015.

21. Li Y, Li L, Guan Y, Liu X, Meng Q and Guo Q: MiR-92b regulate the cell growth, cisplatin chemosensitivity of U2OS non smal cell lung cancer cell line and target PTEN. Biochem Biophys Res Commun 440: 604-610, 2013.

22. Lei L, Huang Y and Gong W: Inhibition of miR-92b suppresses nonsmall cell lung cancer cells growth and motility by targeting RECK. Mol Cell Biochem 387: 171-176, 2014.
23. Wu ZB, Cai L, Lin SJ, Lu JL, Yao Y and Zhou LF: The miR-92b functions as a potential oncogene by targeting on Smad3 in glioblastomas. Brain Res 1529: 16-25, 2013.

24. Niehrs C: Function and biological roles of the Dickkopf family of Wnt modulators. Oncogene 25: 7469-7481, 2006.

25. Fukusumi Y, Meier F, Götz S, Matheus F, Irmler M, Beckervordersandforth R, Faus-Kessler T, Minina E, Rauser B, Zhang J, et al: Dickkopf 3 promotes the differentiation of a rostrolateral midbrain dopaminergic neuronal subset in vivo and from pluripotent stem cells in vitro in the mouse. J Neurosci 35: 13385-13401, 2015.

26. Wang Z, Lin L, Thomas DG, Nadal E, Chang AC, Beer DG and Lin J: The role of Dickkopf-3 overexpression in esophageal adenocarcinoma. J Thorac Cardiovasc Surg 150: 377-385.e2, 2015.

27. Ryu SW, Kim JH, Kim MK, Lee YJ, Park JS, Park HM, Kim DH, Lee SH and Lee EJ: Reduced expression of DKK3 is associated with adverse clinical outcomes of uterine cervical squamous cell carcinoma. Int J Gynecol Cancer 23: 134-140, 2013.

28. Lee EJ, Jo M, Rho SB, Park K, Yoo YN, Park J, Chae M, Zhang W and Lee JH: Dkk3, downregulated in cervical cancer, functions as a negative regulator of beta-catenin. Int J Cancer 124: 287-297, 2009.

29. Li Q, Shen K, Zhao Y, Ma C, Liu J and Ma J: MiR-92b inhibitor promoted glioma cell apoptosis via targeting DKK3 and blocking the Wnt/beta-catenin signaling pathway. J Transl Med 11: 302, 2013.

30. Hoang BH, Kubo T, Healey JH, Yang R, Nathan SS, Kolb EA, Mazza B, Meyers PA and Gorlick R: Dickkopf 3 inhibits invasion and motility of Saos-2 osteosarcoma cells by modulating the Wnt-beta-catenin pathway. Cancer Res 64: 2734-2739, 2004.

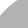

